\title{
Linking the Value Assessment of Oil and Gas Firms to Ambidexterity Theory Using a Mixture of Normal Distributions
}

\author{
Sébastien Casault ${ }^{1}$, Aard J. Groen ${ }^{2}$ and Jonathan D. Linton ${ }^{3 *}$ \\ ${ }^{1}$ NIKOS, Centre for Innovation \& Entrepreneurship, University of Twente, PO Box 217, 7500AE Enschede - The Netherlands \\ 2 Professor of Innovative Entrepreneurship \& Valorisation, NIKOS, Centre for Innovation \& Entrepreneurship, University of Twente \\ \& University of Groningen, Enschede, Groningen - The Netherlands \\ 3 Power Corporation Professor for the Management of Technological Enterprises, University of Ottawa, DMS 6108, 55 Laurier Street, \\ KIN 6N6 Ottawa, Canada and Head of Science Technology Studies Laboratory, National Research University Higher School of Economics, \\ Moscow - Russian Federation \\ e-mail: linton@uottawa.ca \\ * Corresponding author
}

\begin{abstract}
Oil and gas exploration and production firms have return profiles that are not easily explained by current financial theory - the variation in their market returns is non-Gaussian. In this paper, the nature and underlying reason for these significant deviations from expected behavior are considered. Understanding these differences in financial market behavior is important for a wide range of reasons, including: assessing investments, investor relations, decisions to raise capital, assessment of firm and management performance. We show that using a "thicker tailed" mixture of two normal distributions offers a significantly more accurate model than the traditionally Gaussian approach in describing the behavior of the value of oil and gas firms. This mixture of normal distribution is also more effective in bridging the gap between management theory and practice without the need to introduce complex time-sensitive GARCH and/or jump diffusion dynamics. The mixture distribution is consistent with ambidexterity theory that suggests firms operate in two distinct states driven by the primary focus of the firm: an exploration state with high uncertainty and, an exploitation (or production) state with lower uncertainty. The findings have direct implications on improving the accuracy of real option pricing techniques and futures analysis of risk management. Traditional options pricing models assume that commercial returns from these assets are described by a normal random walk. However, a normal random walk model discounts the possibility of large changes to the marketplace from events such as the discovery of important reserves or the introduction of new technology. The mixture distribution proves to be well suited to inherently describe the unusually large risks and opportunities associated with oil and gas production and exploration. A significance testing study of 554 oil and gas exploration and production firms empirically supports using a mixture distribution grounded in ambidexterity theory to describe the value fluctuations for these firms.
\end{abstract}

Résumé - Élaboration du lien entre l'évaluation de la valeur des entreprises pétrolières et gazières et la théorie de l'ambidextrie avec l'aide d'un mélange de distributions normales Les entreprises d'exploration et de production pétrolières et gazières ont des profils de rendement qui ne sont pas entièrement expliqués par la théorie financière courante, notamment, la variation de leurs 
retours est non gaussienne. Dans ce texte, la nature et les raisons sous-jacentes de ces écarts importants par rapport à leurs attentes sont considérées. Une meilleure compréhension par rapport à ces différences de comportement est importante pour plusieurs raisons, dont : les évaluations des investissements, relations avec les investisseurs, les décisions de placement de capitaux, les évaluations de l'entreprise et les mesures de performance de gestion. Nous démontrons que l'utilisation d'une distribution à « queue lourde » telle qu'un mélange de deux distributions normales, représente un modèle beaucoup plus précis que l'approche traditionnelle gaussienne simple pour décrire le comportement de la valeur des entreprises pétrolières et gazières. Ce mélange de distributions normales permet de bien élaborer le lien entre la théorie et la pratique en gestion sans avoir recours à des techniques plus complexes comme des modèles GARCH et à des modèles de diffusion par saut. En plus, la distribution mixte peut aussi servir à quantifier la théorie de l'ambidextrie organisationnelle qui suggère que les entreprises opèrent dans deux états distincts distingués par l'objectif principal de l'entreprise : un état d'exploration qualifié avec un taux d'incertitude élevé ; et, un état d'exploitation (ou de production) avec un taux d'incertitude faible. Les résultats ont des implications directes pour améliorer la précision des techniques d'options réelles et l'analyse de la gestion du risque. Les modèles traditionnels de l'analyse des options supposent que la valeur de ces entreprises suit une marche aléatoire normale. Cependant, un modèle de marche aléatoire normale ignore la possibilité et l'impact de changements importants et rapides dans le marché causés par des événements tels que la découverte de réserves importantes ou l'introduction de nouvelles technologies. La distribution mixte permet de mieux décrire ces types de changements rares mais importants liés à la production et l'exploration pétrolière et gazière. Fondée sur la théorie de l'ambidextrie organisationnelle, une étude de test d'hypothèses en utilisant des données sur le rendement de 554 entreprises d'exploration et de production pétrolières et gazières conforte l'utilisation d'un mélange de distributions normales pour décrire les fluctuations de la valeur de ces entreprises.

\section{ACRONYMS}

$\begin{array}{ll}\text { CAPM } & \text { Capital Asset Pricing Model } \\ \text { KS } & \text { Kolmogorov-Smirnov } \\ \text { MLE } & \text { Maximum Likelihood Estimation } \\ \text { NPV } & \text { Net Present Value } \\ \text { WACC } & \text { Weighted Average Cost of Capital } \\ \text { WTI } & \text { West Texas Intermediate }\end{array}$

\section{INTRODUCTION}

The ability to accurately model price time series is a critical part of studying the dynamics process of value creation. There are many successful techniques that can adequately replicate the structure of these time series (e.g., GARCH, jump diffusion). However, these techniques do not align completely with management theory. We propose a simple modification to normal Brownian motion, which is also consistent with ambidexterity theory, to accurately model the behaviour of oil and gas firms.

The oil and gas industry remains one of the most important industrial sectors in North America and is expected to grow for the foreseeable future based on energy demand predictions (Canada's Energy Future, 2013). A better understanding of how oil and gas firms operate could yield significant benefits. Making incorrect assumptions about investment market behaviour can lead to mistakes in interpreting and responding to sudden fluctuations in market price. Such problems include, but are not limited to:

- inappropriate rewards to managers or others at times of heightened stock prices;

- termination of employees and managers at times of sudden price decline;

- stakeholders such as banks and investors reacting negatively and incorrectly as sudden stock price shifts are misinterpreted;

- potential upside of exploration activities being undervalued through the use of traditional Gaussian real options techniques, which underestimates of volatility.

A better measurement of the value of exploration activities may lead to a more equitable attribution of resources by headquarters to these divisions who would otherwise be competing for resources at the expense of long-term benefits and cooperation (Stein, 1997; Mudambi and Navarra, 2004). Previous internal capital market studies have shown that oil and gas firms tend to reduce non oil investments when oil 
prices crash (Lamont, 1997). This is likely suboptimal as it places oil and gas firms in an un-hedged long physical position. In this sense, exploration activities act as an option to hedge against large crashes.

Oil and gas exploration and production firms are interesting to study, because they do not follow expected patterns of Gaussian market price and that failure appears to be partly due to the dual nature of the firms and to the fact that they produce a highly traded commodity making the dynamics of the price of oil an important factor in the value of these firms' activities.

Oil and gas firms are typically ambidextrous meaning that they rely on concurrent exploration and exploitation activities to create value. Abernathy and Utterback (1978) first suggested that a firm's focus on productivity maximization (e.g., through process definition) inhibited its flexibility and ability to innovate. Later, the idea that firms operate in either exploitation or exploration states was elaborated from the point of view of organizational learning (March, 1991).

Both states can coexist within the same organization concurrently and this is known as ambidexterity (Levinthal and March, 1993). Exploration is usually characterized by large variances generated by uncertainty while exploitation provides stability (He and Wong, 2004; Mudambi and Swift, 2011). Successful firms operate between periods of stable and consistent investments in exploration followed by short transition periods where entrenched exploration-related interests are "uprooted" to maximize the performance of the explorative activities in general (Mudambi and Swift, 2014).

This theory complements current theories on utility maximization and risk minimization. For example, both managers who are risk adverse and those who tolerate risk can increase their utility by concentrating on exploration activities in order to reduce their downside risk (Menezes et al., 1980). Although individual explorative activities are characterized by uncertainty of outcome, these can be justified as an activity that lowers risk overall.

Second, traditional economic models that stipulate that firms' value profiles undergo Gaussian random walks are inappropriate as the value of these firms is also closely linked with the changes in the price of the commodities that they produce. Specifically, there is a strong correlation between the price of the commodity and the change in the value of firms. For example, a more accurate statistical description for the West Texas Intermediate (WTI) index is provided using a mixture distribution - as this index is non-Gaussian. This dual nature of the firms is such a fundamental property of this commodities market that it appears to manifests itself at the index level.

Traditional economic and financial tools typically assume that the asset can be adequately modeled or approximated as undergoing a geometric random walk (Black and
Scholes, 1973). A random walk is a process by which a path (i.e., the price of an asset) consists of a succession of random steps. The 'geometric' part implies that the logarithmic difference between two consecutive steps is taken from a Gaussian (or normal) distribution. This leads to expected returns that rarely go above or below two units of standard deviation from their mean value. It is important to get the dynamics right, because this normal assumption is used to value derivatives such as options. In practice, investors recognize that empirical return distributions exhibit kurtosis and skew. This is corrected by introducing an ad hoc implied volatility term. Plotting implied volatilities against strike prices for a given expiry produces a parabola, or "smile", instead of the expected flat surface. This was a significant finding because the resulting surfaces are relatively stable and can be obtained a priori. However, a better initial assumption about the distribution of returns that is able to capture the main dynamics described by volatility surfaces (i.e., skew and the kurtosis) for the underlying asset would be more valuable (Bahra, 1996).

Compared with other types of firms, oil and gas firms are faced with a relatively high level of uncertainty. There is regulatory uncertainty due to the fact that they operate systems that frequently cross numerous geo-political boundaries with little regulatory consistency between those jurisdictions (Mansell and Church, 1995). There is also, more importantly, uncertainty related to the nature of exploration itself. For example, the value of a firm can suddenly increase by large amounts if a play turns out to have a greater yield than expected, for example. Lastly, sudden changes in technology can also lead to efficiency gains that could potentially translate into rapid changes in the value of these firms. These types of uncertainty all contribute to increase the empirical volatility of these firms. Ambidexterity theory is particularly well suited to describe oil and gas companies. New wells are discovered through exploration. The firm must then transition to a more exploitative state without losing its ability to discover new wells in the future. As the extant oil wells mature or as new capital becomes available for growth, the firm switches back toward exploration activities.

Previous studies have shown that firms that perform R\&D are ambidextrous and can be well described using a mixture distribution (Casault et al., 2014). We show here that a model based on a mixture distribution also provides more accuracy in valuing oil and gas exploration and production assets. The usage of the mixture distribution was studied before and applied to a variety of assets such as foreign currency (Bahra, 1996). This distribution was also previously shown to be superior in describing the non-Gaussian process of oil price returns (Meade, 2010) and other futures markets (Ané and Labidi, 2001).

A more accurate value model can improve corporate governance and financial planning. Understanding the 
scope of volatility and the impact of uncertainty on the value of the firm can help managers set aside an appropriate amount of resources to weather periods of exploration that are associated with higher risk and volatility in the firms' value. From a financial lender's perspective, a more accurate understanding of the effect of exploration on a firm's volatility profile can help set expectations and provide a baseline level of volatility that can be reasonably expected. This provides additional assurances to the lenders as to whether or not the firm is behaving within normal parameters or not, despite the increased volatility. One of the main reasons that projects do not achieve their intended goal is often uncertainty (Bratvold and Begg, 2008). Studies have shown that uncertainty and volatility in the value of oil has real macroeconomic impacts in American and Canadian markets (Hamilton, 1983; Elder and Serletis, 2009). A more accurate model will help risk management and may additionally ease this uncertaintydriven negative driver.

There are generally two types of approaches that are used to model the price dynamics of assets: classical and statistical (Meade, 2010 for an overview of these techniques for oil futures). The classical types are typically concerned with modeling the dynamic process itself using a variant of Brownian motion (e.g., jump diffusion, mean reversion). The statistical techniques study distribution functions that explain the static properties of the returns' distributions without directly modeling the process that creates the distribution. See Sadorsky (2006) for an example that models the price dynamics of the oil futures using GARCH models. As mentioned before, we take a more empirical statistical approach and look at the resulting distribution function, which provides a more accurate model (Benth and Šaltytė-Benth, 2004 for similar approach). However, we add value to the statistical approach by grounding the resulting observations in ambidexterity theory, which explains the dynamic process that results in this behavior.

From a decision support standpoint, as new information on the potential outcomes of a firm's investment becomes available, management typically adjusts its strategy. This type of flexibility enhances the exploration investment's value by limiting the potential downside losses and preferentially selecting positive outcomes resulting in an asymmetric returns distribution in favor of the initial investment - at least statistically (Bratvold and Begg, 2008). In contrast, commonly used techniques such as Net Present Value (NPV) do not account for this reduction in uncertainty over time and the value of managerial flexibility. This is especially true for assets with relatively unconstrained upside potential such as exploration activities. NPV techniques are especially inaccurate for oil and gas investments that have returns over longer time frames (i.e., decades) due to its extreme sensitivity to the selection of a risk-adjusted discount rate. Even the most positive scenario-based analysis often leaves projects under-valued (Smith and McCardle, 1999).

The Weighted Average Cost of Capital (WACC) is often used to calculate an appropriate discount rate for oil and gas projects. It explicitly relies on the assumption that the future dynamics of the value of the project will be normal (Smith and McCardle, 1999). The WACC, using a Capital Asset Pricing Model (CAPM), compares the firm (or a project) to a group of comparable traded assets. This appears unrealistic on a project level given the fact that the return distribution for long-term projects is highly skewed, as discussed earlier. Further, there is no way to guarantee that the comparable traded assets used for comparison are managed using a similar risk profile.

In reality, there is a positive selection bias accomplished by resolving uncertainty simply by taking an active information gathering exploration investment strategy (Childs and Triantis, 1999). This process involving a series of management decisions - or real options - is analogous to options on financial markets and can significantly increase the investment value. Real option analysis lends itself particularly well to oil and gas valuation and has been studied before (Chorn and Shokhor, 2006). A better model describing the dynamics of ambidextrous firms that engage in both exploration and exploitation activities will likely lead to financial tools that put a premium on these activities if they are effectively managed in portfolios in order to take advantage of their statistical value creation properties.

Such a model would have a positive impact in our ability to make quantitative decisions about investments related to assets characterized by high volatility. For example, an increased predictability in the frequency and amplitude of volatility would improve investor relations. More realistic operating volatility boundaries could be calculated. A better understanding of expected volatility profiles would also improve relations with bankers. This is important since bankers could potentially remove support of companies that suddenly appear too risky based on their volatility profiles when in fact these companies are investing in exploration activities and are operating within expected volatility boundaries for such activities (and might turn out to be quite profitable). Lastly, this could help firms to manage expectations internally (i.e., giving bonuses associated when returns are positive or implementing drastic cost reductions when returns are negative). A better model would allow management to set aside more appropriate cash reserves to weather expected fluctuations.

Understanding whether or not sudden swings in stock price - and the duration of time where the price is affected - are within a typical range or if they are in an abnormal range is critical information in helping management decide on a response strategy. Further, this would allow managers and investors a more accurate understanding of the relative 
risk (i.e., both downside and upside value) associated with exploration activities such that they can be valued appropriately. Current cost of capital and option methodologies concentrate on finding a corresponding proxy index with a similar $\beta$ in order to extract risk from its variance, $\sigma$. This assumes that the asset will evolve according to a Gaussian distribution, which we will show not to be the case for these assets. By simply looking at $\sigma$, there is a tendency to undervalue assets due to an underestimation of the potential larger gains than expected, at least statistically at a portfolio level. Finally, a better understanding of the nature of share price swings can help the firm make decisions for acquisition of capital (e.g., equity or loan) at times that is most suitable.

\section{METHODOLOGY}

\subsection{Firm Selection}

Since there are no historical time-series that allow us to estimate the uncertainty of exploration activities in oil and gas projects, we must use a suitable indicator that will function as a proxy to describe this dynamic behavior. The pharmaceutical firm Merck has successfully used stock price volatility in order to approximate the volatility of the NPV of future cash flows resulting from pharmaceutical R\&D (Nichols, 1994; Bowman and Moskowitz, 2001). We argue that a comparison can be made between the behavior of $R \& D$ on the value of the firm and the behavior of exploration on the value of oil and gas firms. Like R\&D, many investments in exploration activities are irreversible; the market value of the product does not change the cost and commercialization of exploration activities. Consequently, we can use firms' stock quotes as first order approximations of the market value placed on these firms' exploration efforts.

We begin by identifying North American oil and gas exploration and production firms using Bloomberg (Bloomberg Markets, 2014). The stock prices of these firms were obtained to three decimal precision using QuoteMedia's online stock quotes. All available quotes were extracted for the time period between 2002 and 2012. Firms were then further screened to ensure that stock prices were available for at least 200 consecutive days of trading in the above-specified time period. This resulted in retaining 554 firms for further analysis.

Using the list of 554 retained firms' stock prices, the logreturns, $\eta$, were calculated for these remaining qualifying firms. The log-returns are a first order approximation of the arithmetic returns:

$$
\eta(t)=\frac{S(t+1)-S(t)}{S(t)} \simeq \log S(t+1)-\log S(t)
$$

where $S(t)$ and $S(t+1)$ are the stock prices for consecutive time intervals. In the case of this study where we are analysing daily returns, or returns taken between two consecutive trading days. This results in 554 time series containing at least 200 data points describing the daily returns of our firms. That is, the daily relative value fluctuations in the future commercial value of those firms' combined exploration and production activities. These time series are then transformed into static histograms that describe each firm's value return distribution profile. We argue that the histograms have two distinct Gaussian components: one with a high variability to account for mainly explorative activities and, a second with a low variability describing the low uncertainty production activities.

\subsection{Correlation with Commodity Index}

As mentioned earlier, the movements observed in the price of the oil commodity index influence changes in the price of oil and gas firms. For example, the WTI index's daily price is shown in Figure 1. This figure shows a relatively steady growth in price with the exception of several instances of rapid and large fluctuations. This kind of behavior is not well described by traditional Gaussian models and leads to an underestimation in the dynamics of this process.

We demonstrate that models that can account for these types of departures from normality can provide a more accurate description of this index. For example, Figure 2 shows a

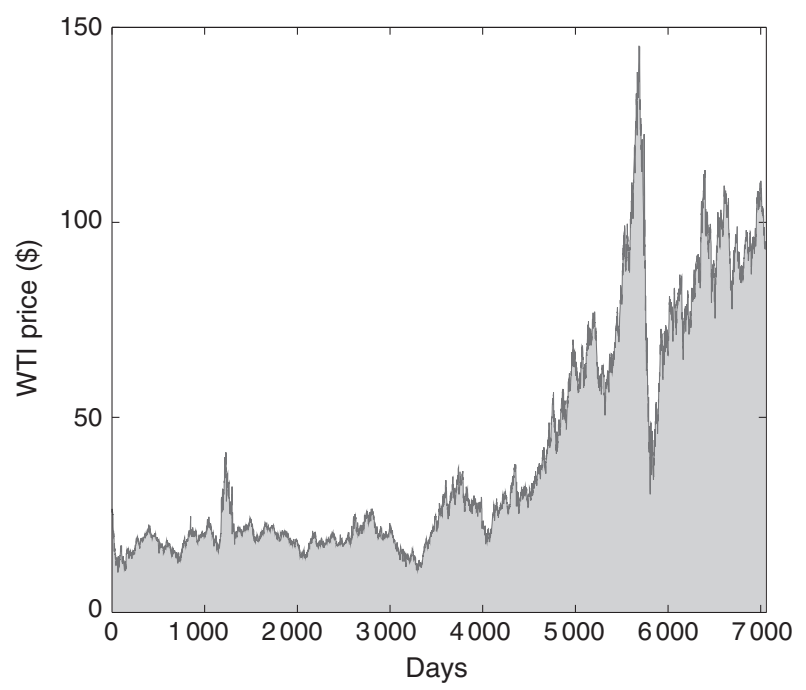

Figure 1

WTI daily price quotes for a period of time between 1986 and 2013. The profile shows relatively steady growth interspersed with rapid and large changes in the price of oil occurring on several occasions. 


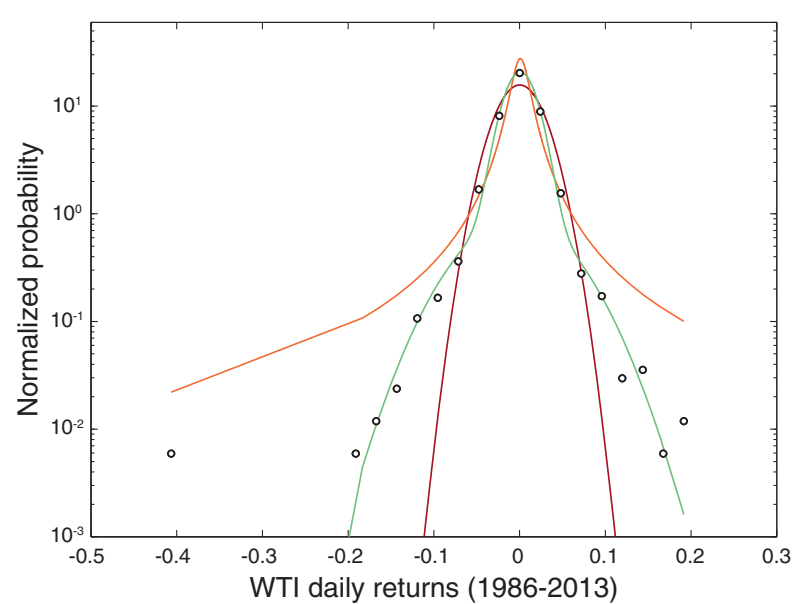

Figure 2

\begin{abstract}
Histogram of the WTI price returns for the period shown in Figure 1. The histogram is fitted with a normal, power law and mixture distribution functions with $p$-values of $0.00,0.06$ and 0.00 , respectively. This indicates that the data appear to be taken from a mixture distribution. The sole outlier around -0.4 coincides with the US presidential announcement declaring war on 16 January 1991.
\end{abstract}

histogram of the WTI returns together with normal, power law and mixture distribution fits. Significance testing on the three distribution shows that the data appear to come from a mixture distribution with a $p$-value of 0.06 (and zero for the other distributions). Fitting parameters for this distribution are (Eq. 2) $p=0.12, \mu_{1}=-0.0041, \sigma_{1}=0.055$, $\mu_{2}=0.00078$ and $\sigma_{2}=0.018$. As a comparison, the SP500 index has an average volatility $\sigma=0.014$ for the same time period (this is an approximation because the volatility of the index is not constant over time and fluctuates between 0.008 and 0.017 ). This indicates that the exploration component of this index contributes to volatility approximately four times greater than the industry index whereas the core business component of this index has a volatility profile that is similar to the industry index.

It is important to understand how the WTI price fluctuates because the value of oil and gas firms are closely linked to these movements. Previous studies have shown significant correlations between the price of oil, stock indices, world events and individual firms' stock price (Filis et al., 2011; Kollias et al., 2013; Reboredo and Rivera-Castro, 2014; Liu, 2014).

We also studied the statistical cross-correlation function between the index and all firms' stock quotes in our data set, which provides a correlation factor $(-1$ is perfectly anti-correlated, 0 is not correlated and 1 is perfectly correlated). Significant cross-correlation between the majority of firms and the index is persistent at different intervals.
This is significant and confirms that the firms follow the WTI prices, at least to a good first order approximation. Since we have shown that the WTI is best described using a mixture distribution, it lends credibility to the fact that those firms' values will also have a significant contribution from such a distribution.

\subsection{Significance Testing of Model}

The return time series were fitted by a Maximum Likelihood Estimation (MLE) technique with two probability distribution functions. First, it is fitted with a normal Gaussian distribution, which, according to theory, is the most widely used description of firms' returns and should provide a decent fit. Second, the empirical time series is also fitted with the following five-parameter stable distribution function that is a mixture of two normal distributions. The mixture distribution, $f(\eta)$, is expressed as:

$$
\begin{aligned}
f\left(\eta ; p, \sigma_{1}, \sigma_{2}, \mu_{1}, \mu_{2}\right)= & p \frac{1}{\sqrt{2 \pi \sigma_{1}^{2}}} e^{-\frac{\left(\eta-\mu_{1}\right)^{2}}{2 \sigma_{1}^{2}}} \\
& +(1-p) \frac{1}{\sqrt{2 \pi \sigma_{2}^{2}}} e^{-\frac{\left(\eta-\mu_{2}\right)^{2}}{2 \sigma_{2}^{2}}}
\end{aligned}
$$

with means $\mu_{1}$ and $\mu_{2}$ and variances $\sigma_{1}$ and $\sigma_{2}$. We also introduce $0 \leq p \leq 1$ as a mixing parameter. This mixing parameter also implicitly acts as an amplitude parameter for each of the two Gaussian components of the mixture distribution.

This resulted in two fits for each of the 554 firms under evaluation (i.e., the simple Gaussian and the mixture of two Gaussian fits). In order to measure the goodness of fits, the Kolmogorov-Smirnov (KS) test was used. This test was chosen for its computational simplicity and is shown to be relatively accurate and comparable to other, more sophisticated, goodness of fit tests (Anderson-Darling test) (Clauset et al., 2009). The KS test measures the maximum distance between the empirical and theoretical best fit cumulative distribution functions and can be used to evaluate whether or not empirical data are distributed according to a specific distribution.

This results in quantitative measures (i.e., the KS distance) describing the appropriateness of using a single Gaussian distribution versus the use of our proposed mixture distribution for each firm. To get significance testing, we evaluate the empirical $p$-value for each fit by generating bootstrap datasets using the fitting parameters obtained in in the MLE step. The $p$-value is calculated by counting the ratio of the number of times that $\mathrm{KS}$ distance for the empirical data and its corresponding best fit is smaller than between the bootstrap datasets and their corresponding best fits. 
Normally a $p$-value $>0.05$ is used to provide evidence that the tested distribution function has adequate descriptive properties. These two iterative processes are used throughout this article to estimate best of fit parameters and to evaluate the distribution function's descriptive ability.

This methodology is meant to serve as a robust guide to testing for normality of our firms' return profiles while also offering and testing the validity of a new, simple, model of punctuated equilibrium that describes the bimodal nature of value extraction associated with concurrent exploration and production activities. To recap, the KS measure provides a comparative tool that shows how good a fit is compared to another and the $p$-value provides significance evidence that indicates whether or not empirical data can be said to come from a specific distribution.

\subsection{Additional Considerations}

Another consideration was performed in order to analyse the return time series of our 554 oil and gas firms. This sector has a sparse trading history with most firms not trading on a daily basis. In fact, on average, these firms do not trade approximately $40 \%$ of the time. Incorporating the days where there is no trading results in a histogram that has a large peak at $\eta=0$, which can only be properly modeled using a discontinuous function with an inflection point at the origin (Fig. 3).

While it is possible that a number of those zero-return days are due to markets having efficiently equilibrated to the appropriate price of the firm, the majority of these zero-return days could be due to sparse trading and therefore do not provide useful information on the dynamics of the value creation mechanisms in these firms. Consequently, the impact of removing all zero-trading days from the analyses is considered.

\section{RESULTS}

\subsection{Illustrative Case Study - American Energy Group}

American Energy Group (Fig. 4) offers a typical example of the type of stock quote time series that is observed. It appears to be dominated by normal behavior, interspersed with rapid and large fluctuation events over the eight-year period. Another feature that is common to many of the firms is that there are several instances of sparse trading resulting in periods of stable prices. Although it is possible that the firm's value is deemed accurate over these periods, the fact that this behavior occurs with many of the thinly traded firms suggests that many firms do not trade regularly and that removing these data points from the analysis for each firm would not result in a loss of important dynamic information. In the case of the American Energy Group (Fig. 5), removal of days with no returns account for $24 \%$ of the total number of days.

Figure 5 shows a histogram of the daily returns calculated from the stock quotes shown in Figure 4. This histogram shows that the 'normal' Gaussian distribution does not provide a good fit to describe the dynamic value process of this firm. The Gaussian distribution, shown as the red line $(p$-value $=0.000, \mu=-4.57 \mathrm{e}-4, \sigma=0.138)$, does not appropriately capture the full behavior of this firm because it overcompensates on the variance at the expense of the

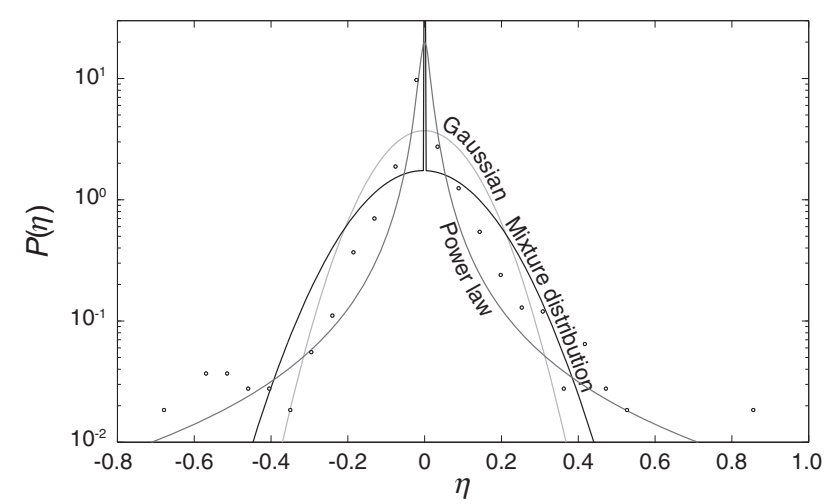

Figure 3

Histogram of returns for the company American Energy Group Ltd. (OTCMKTS:AEGG) on a semi-log chart. The frequency of zero returns is such that it makes it impractical to fit using continuous distribution functions.

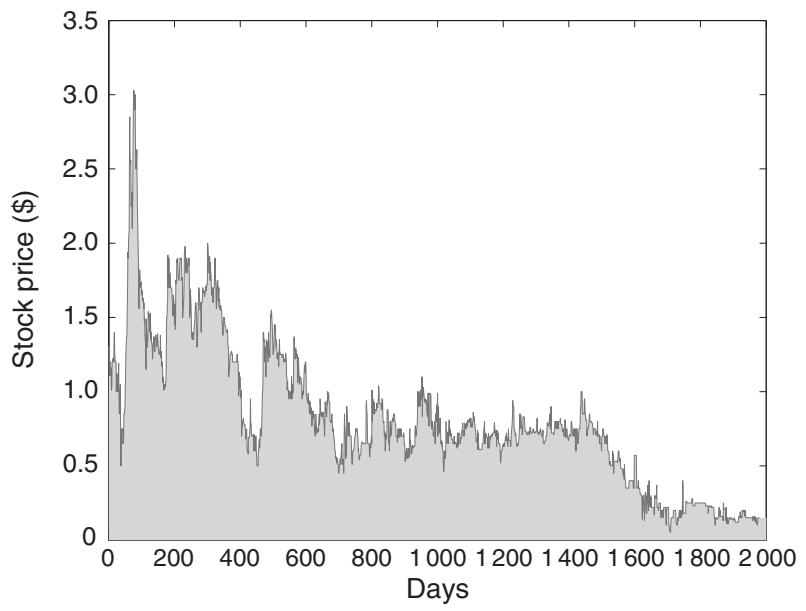

Figure 4

Daily stock quotes for American Energy Group between 2004 and 2013. 


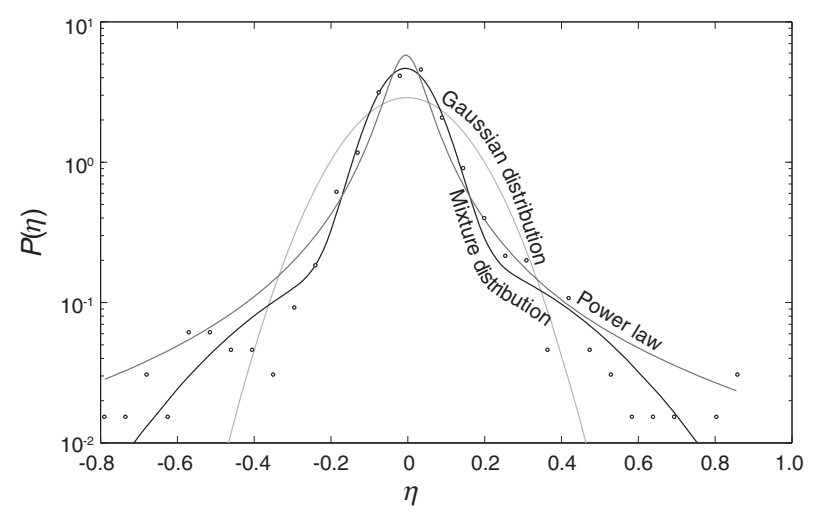

Figure 5

Histogram of the stock returns for the company American Energy Group shown as the open circles. Gaussian distribution best fit ( $p$-value $0.000, \mu=-4.57 \mathrm{e}-4, \sigma=0.138$ ). A power law, such as the Cauchy distribution ( $p$-value $=0.001, A=0.055$, $\mu=-0.005)$. Mixture of two Gaussian ( $p$-value $=0.136$, $\left.p=0.170, \mu_{1}=0.028, \sigma_{1}=0.290, \mu_{2}=-0.006, \sigma_{2}=0.074\right)$.

central portion of the returns. A power law, such as the Cauchy distribution shown in green provides a better fit than the Gaussian distribution ( $p$-value $=0.001$, $A=0.055, \mu=-0.005$ ). The Cauchy distribution was shown to provide a good fit of the thick tail behaviour of R\&Dspecific activities in the past (Casault et al., 2013). However, the mixture of two Gaussians, shown as the blue line $\left(p\right.$-value $=0.136, p=0.170, \mu_{1}=0.028, \sigma_{1}=0.290$, $\left.\mu_{2}=-0.006, \sigma_{2}=0.074\right)$, provides the best fit for this company's overall return profile - likely due to its exploration and exploitation dual nature.

The heavier tailed mixture distribution is able to capture some of the high fluctuation dynamics of the firm while being able to properly model the stable portion of the firm's returns near the origin. Additionally, the mixture distribution - unlike many heavy tailed distributions - has defined first and second moments and converges rapidly outside of the area of interest. Using this distribution is also supported by ambidexterity theory, which explains how oil and gas firms create value concurrently from production and exploration activities. This dual nature is persistent and observable in the stock price returns - an interesting and important finding.

\subsection{Expand Analysis to all Firms}

Using the methodology just described for American Energy Group, analysis was extended to the full dataset of 554 firms. Significance testing was utilized to show that the mixture distribution is a better fit for these firms. Each firm was fitted with a normal, a power law and a mixture distribution using the method of MLE. After which, 1000 bootstrap data series were generated using the best fit MLE parameters obtained for each firm from all three distribution. These bootstrap data series were fitted with their respective theoretical distribution functions and the KS distances were obtained for each set of empirical/bootstrap versus theoretical sets. For each firm, a $p$-value was extracted using all three fits by getting the ratio of the number of times that the KS measure was larger for the bootstrap data set than the empirical data.

Of the 554 firms, 543 (or 98\%) of the firms had a KS measure that favoured a mixture distribution over a normal Gaussian distribution. Of those 543 firms, 471 firms had a $p$-value $>0.05$ indicating that $87 \%$ of those firms have returns that are distributed according to the mixture distribution.

The mean values of the two components are as follows: $\sigma_{1}=0.345$ and $\sigma_{2}=0.0802$. For reference purpose the volatility obtained for the oil index (fitted with a mixture distribution) of $\sigma_{1}=0.055$ and $\sigma_{2}=0.018$ and to the volatility of a stable market index such as the SP500, with volatility $\sigma=0.014$ is provided. In the case of the firms, the larger volatility represents the uncertainty associated with those firms' exploration activities (e.g., prospecting, well construction, preproduction). The smaller value of volatility and its associated Gaussian component can be used to represent the firms' core business, characterized by a high degree of stability. In the next section, how these two components can potentially be used as a measurement of the firms' efficiency is considered.

For comparison, of the 554 firms, 447 (or $81 \%$ ) of the firms had a KS measure that favored a power law distribution over a normal Gaussian distribution. The mixture distribution provides an overall better fit and is better supported by management theory, however, we provide this thick tailed power law distribution as an alternative that can also be considered when describing high volatility assets. The power law distribution is actually complicated to use in practice due to its lack of convergence and analytical complexity.

This provides a significant analytical support for the fact that exploration and production oil and gas firms have value dynamics that can be well modeled using a mixture distribution. This is due to the concurrent exploration and production activities (exploitation) that are closely tied to the commercial of the firms combined with the fact that we have shown earlier that these firms are well-correlated with their primary commodity's price movements, which we have shown also to be well-described by a mixture distribution.

\subsection{Significant Properties of the Mixture Distribution}

The impact of market inefficiencies can be estimated by looking at the peak difference between the empirical distribution with the zero returns intact and the estimated peak 
using the best fit after having removed the days with no return. This will show the amount of days, on average, that the firm does not trade due to market inefficiencies.

Some interesting information can be extracted from the two Gaussian components. The location of each component's mean and the gap between the two components' mean, $\Delta \mu$, can potentially provide important information about performance of both business lines of the firms. For example, assume (as is the case for most of our observed firms) that $\sigma_{1}>\sigma_{2}$, which means that the curved associated with $\sigma_{1}$ is related to the firm's exploration and high volatility activities.

In this case, the value of $\mu_{1}$ will provide an indication of the firm's success in capitalizing the value of their exploration activities. If $\mu_{1}>\mu_{2}$ and $\mu_{1}>0$, this offers a good sense that the firm's exploration activities are the firm's cash driver and there might be potential for improving the firm's overall value by bringing efficiencies to production activities. However, if $\mu_{1}<\mu_{2}$ or if $\mu_{1}<0$, the firm should rethink its exploration strategy because it is either not performing as well as its production activities or it is a net drain on the firm's value.

Looking at firms that were better described using a mixture of Gaussian distribution additionally yields a surprisingly linear relationship between the two values of $\sigma$ optimally found by the MLE algorithm for the individual component distributions. Statistically, one of the two curves exhibits variability on the order of six times that of the other

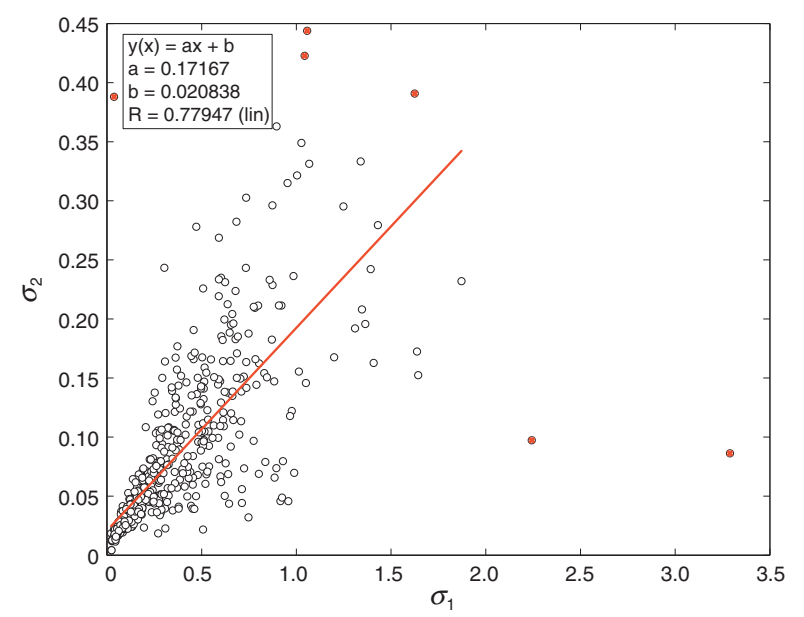

Figure 6

This chart shows a relationship between the variance of the two curves that make up the best mixture distribution to describe the empirical data. This suggests an approximately six to one ratio of the two normal distributions meaning that the firms exist in a mixture of two normal states where one is characterized by variability larger than its steady state. The line of best fit was obtained by excluding data points considered outliers (shown in red). curve as shown in Figure 6. By removing only 6 (or 1\%) of the outlying data points (shown in red). The following linear relationship is shown between the two components of variability:

$$
\sigma_{2}=0.172 \sigma_{1}+0.002
$$

This is a significant finding indicating that the firms operate in two linked states governed by similar Gaussian mechanisms. One state characterized by larger fluctuations and a higher variability and another more steady state mode characterized by smaller fluctuations and that there is a relationship between the two modes as indicated by the above equation. This relationship shows that that $\sigma_{1}$ is approximately six times larger than $\sigma_{2}$ for the firms in our sample. This high variability curve appears to be necessary in modeling the behavior of these assets. Namely, to statistically account for infrequent, large, and rapid fluctuation events that appear to consistently occur with these types of firms.

One of the useful consequences of this finding is that managers of oil and gas firms or financial investors have an estimate for the expected variability in periods of high volatility based on the variability observed in periods where the firm's price is relatively stable. This can be used to quantitatively assess the financial impact of uncertainty related to investments in exploration activities, which tend to increase a firm's volatility profile. That is, a firm can expect to see variability approximately six times greater than normally observed when a significant portion of its resources are diverted to investments in exploration. This information may be valuable in making the necessary financial preparations in advance of significant investments in exploration activities. Prior awareness of the extent of the variation is also of value for assessment of financial healthiness by the management of team and communication with stakeholder - such as stockowners, analysts and media.

\section{CONCLUSION}

In this study, North American oil and gas exploration and production firms are shown to have return profiles that have features that are not adequately captured using traditional economic and financial models. Namely, these firms have return profiles that show distinct periods of rapid and large fluctuation in stock value. This is a result of the nature of the fluctuations in the commodity that is produced and also by the ambidextrous nature of these exploration and production firms.

A mixture of two Gaussian distribution is more accurate in statistically describing the return profiles of these types of firms over time as they operate in two distinct exploration and production states simultaneously. $98 \%$ of the firms studied in this paper were better described by a Gaussian mixture 
distribution than a single normal Gaussian distribution. Further, $p$-value statistics indicate that the mixture distribution is valid for approximately $87 \%$ of the firms.

The Gaussian mixture distribution provides a better model because the value profile of these firms is thicker tailed and because of these firms' inherent dual nature. The mixture model allows for one of the component to capture low probability, high fluctuation events by which, the firm can extract large profits from (or undergo loss). The resulting thick tail component of the firms' profile contributes to at least one quarter of the overall return profile for most firms studied. We also showed that there is a strikingly linear relationship between the two Gaussian components that form the mixture distribution. This relationship can provide insight to decision makers when about to make investments in higher volatility exploration activities. That is, they can expect their firms' volatility to undergo fluctuations of about six times greater than what they experience in steady state periods. These findings are significant because it suggests that these firms can expect to undergo periods of high volatility roughly one quarter of the time - with an increase in volatility of about $6: 1$.

This study extends the body of knowledge surrounding the effects of exploration on the value of oil and gas firms. A novel statistical methodology allowing one to measure firm transitions between a steady exploitative state and an exploration state characterized by larger variability is provided. This study allows for a better model of the value extraction process of these firms and can lead to financial tools that are more accurate, that can appropriately value the large commercial opportunities generated by exploration activities while placing a premium on such firms.

\section{ACKNOWLEDGMENTS}

This work was funded in part through facilities provided by the Canadian Foundation for Innovation and grants from the Natural Sciences and Engineering Research Council (NSERC) and Social Science and Humanities Research Council (SSHRC). The financial support from the Government of the Russian Federation within the framework of the Basic Research Program at the National Research University Higher School of Economics and within the framework of implementation of the 5-100 Programme Roadmap of the National Research University Higher School of Economics is acknowledged.

\section{BIOGRAPHIES}

Sébastien Casault holds a Ph.D. from the Department of Business Administration at the University of Twente and an M.Sc. in Physics from the University of Ottawa.
Dr. Casault's research focuses on the valuation of exotic options and the use of real options in situations characterized by extreme and non-Gaussian volatility. $\mathrm{He}$ is currently Senior Quantitative Specialist for an energy company located in Calgary, Alberta where he is leading the development of advanced stochastic valuation models to manage risk positions using spread options.

Dr. Aard J. Groen holds a double position on Innovative Entrepreneurship and Valorization at the University of Twente and University of Groningen. Aard is dean entrepreneurship for the University of Groningen and founder and director of NIKOS (the Netherlands Institute for Knowledge Intensive Entrepreneurship) at the University of Twente. Dr. Groen's research focuses on social system analysis of entrepreneurial ecosystems and on processes of technology based entrepreneurship and business development. Groen is CEO of Venturelab International b.v. a living lab for accelerator method development.

Jonathan D. Linton, Ph.D., P.Eng. is the Power Corporation Professor for the Management of Technological Enterprises at the University of Ottawa, the Head for the Science Technology Studies Laboratory of the Higher School of Economic of the National Research University in Moscow, and the Editor-in-Chief of Technovation: The Journal of Technological Innovation, Entrepreneurship and Technology Management. His research is in the areas of sustainable supply chain; management of emerging technologies; and Science, Technology, Innovation policy. He is widely published in both academic and trade journals.

\section{REFERENCES}

Abernathy W.J., Utterback J.M. (1978) Patterns of industrial innovation, Tech. Rev. 80, 40-47.

Ané T., Labidi C. (2001) Revisiting the finite mixture of Gaussian distributions with application to futures markets, J. Futures Markets 21, 347-376.

Bahra B. (1996) Probability distributions of future asset prices implied by option prices, Bank of England Quarterly Bulletin, August, 299-311.

Benth F.E., Šaltytė-Benth J. (2004) The normal inverse Gaussian distribution and spot price modelling in energy markets, Int. J. Theo. App. Fin. 7, 177-192.

Black F., Scholes M. (1973) The pricing of options and corporate liabilities, J. Pol. Econ. 81, 637-654.

Bloomberg Markets (2014) Oil Comp-Explor\&Prodtn Companies. Retrieved February 23, 2014 from http:/www.bloomberg.com/ markets/companies/oil-comp-explor-prodtn/.

Bowman E.H., Moskowitz G.T. (2001) Real options analysis and strategic decision making, Org. Sci. 12, 772-777.

Bratvold R.B., Begg S.H. (2008) I would rather be vaguely right than precisely wrong: A new approach to decision making in the petroleum exploration and production industry, AAPG Bulletin 92, 1373-1392. 
Canada's Energy Future (2013) Energy Supply and Demand Projections to 2035. Retrieved February 23, 2014 from http://www. neb-one.gc.ca/clf-nsi/rnrgynfmtn/nrgyrprt/nrgyftr/2013/nrgftr2013eng.htm.

Casault S., Groen A.J., Linton J.D. (2013) Examination of the behavior of R\&D returns using a power law, Sci. Pub. Pol. 40, 219-228.

Casault S., Groen A.J., Linton J.D. (2014) Improving value assessment of high-risk, high-reward biotechnology research the role of "thick tails", New Biotech. 31, 172-178.

Childs P.D., Triantis A.J. (1999) Dynamic R\&D investment policies, Manage. Sci. 45, 1359-1377.

Chorn L.G., Shokhor S. (2006) Real options for risk management in petroleum development investments, Energy Econ. 28, 489-505.

Clauset A., Shalizi C.R., Newman M.E.J. (2009) Power-Law Distributions in Empirical Data, SIAM Rev. 51, 661-703.

Elder J., Serletis A. (2009) Oil price uncertainty in Canada, Energy Econ. 31, 852-856.

Filis G., Degiannakis S., Floros C. (2011) International Review of Financial Analysis, International Rev. Fin. Anal. 20, 152-164.

Hamilton J.D. (1983) Oil and the macroeconomy since World War II, J. Pol. Econ. 91, 228-248.

He Z.L., Wong P.-K. (2004) Exploration vs. Exploitation: An Empirical Test of the Ambidexterity Hypothesis, Organization Science 15, 4, 481-494.

Kollias C., Kyrtsou C., Papadamou S. (2013) The effects of terrorism and war on the oil price-stock index relationship, Energy Econ. 40, 743-752.

Lamont O. (1997) Cash Flow and Investment: Evidence from Internal Capital Markets, J. Fin. 52, 83-109.

Levinthal D.A., March J.G. (1993) The Myopia of Learning, Strat. Manage. J. 14, 95-112.

Liu L. (2014) Cross-correlations between crude oil and agricultural commodity markets, Physica A 395, 293-302.
March J.G. (1991) Exploration and exploitation in organizational learning, Org. Sci. 21, 71-87.

Mansell R.L., Church J.R. (1995) Traditional and incentive regulation: applications to natural gas pipelines in Canada, Van Horne Institute for International Transportation and Regulatory Affairs, Calgary, CA.

Meade N. (2010) Oil prices - Brownian motion or mean reversion? A study using a one year ahead density forecast criterion, Energy Econ. 32, 1485-1498.

Menezes C., Geiss C., Tressler J. (1980) Increasing Downside Risk, American Econ. Rev. 70, 921-932.

Mudambi R., Navarra P. (2004) Is Knowledge Power? Knowledge Flows, Subsidiary Power and Rent-Seeking within MNCs, J. Int. Bus. Stud. 35, 385-406.

Mudambi R., Swift T. (2011) Proactive R\&D management and firm growth: A punctuated equilibrium model, Res. Pol. 40, 429-440.

Mudambi R., Swift T. (2014) Knowing when to leap: Transitioning between exploitative and explorative R\&D, Strat. Manage. J. 35, 126-145.

Nichols N.A. (1994) Scientific management at Merck: an interview with CFO Judy Lewent, Harvard Bus. Rev. 72, 88-99.

Reboredo J.C., Rivera-Castro M.A. (2014) International Review of Economics and Finance, Int. Rev. Econ. Fin. 29, 145-176.

Sadorsky P. (2006) Modeling and forecasting petroleum futures volatility, Energy Econ. 28, 467-488.

Smith J.E., McCardle K.F. (1999) Options in the real world: lessons learned in evaluating oil and gas investments, Op. Res. 47, 1-15.

Stein J.C. (1997) Internal Capital Markets and the Competition for Corporate Resources, J. Fin. 52, 111-133.

Manuscript submitted in August 2014 Manuscript accepted in May 2015 Published online in September 2015

Cite this article as: S. Casault, A.J. Groen and J.D. Linton (2016). Linking the Value Assessment of Oil and Gas Firms to Ambidexterity Theory Using a Mixture of Normal Distributions, Oil Gas Sci. Technol 71, 36. 